\title{
Anterograde Ventricular Irrigation During Fourth Ventricle Region Surgery
}

\author{
Ian G. Fleetwood, Mark G. Hamilton
}

\begin{abstract}
Objective: To reduce postoperative hydrocephalus following surgery in the region of the fourth ventricle. Method/technique: We describe the use of a conventionally placed lateral ventricular catheter to facilitate anterograde ventricular irrigation during surgery in the region of the fourth ventricle. This technique offers a safe alternative to more conventional approaches to fourth ventricular irrigation and obviates the need for placement of a third or fourth ventricular catheter and/or serial lumbar punctures by thoroughly flushing blood and tissue debris from the operative field at the time of surgery. Results: Preliminary results spanning a five-year period show a lower incidence in the need for early ventriculo-peritoneal shunts (5\%) and delayed ventriculo-peritoneal shunts (10\%). Conclusion: This technique represents a safe method of reducing hydrocephalus following operative procedures in the region of the fourth ventricle.
\end{abstract}

RÉSUMÉ: Irrigation ventriculaire antérograde au cours de la chirurgie de la région du quatrième ventricule. Objectif: Réduire l'hydrocéphalie postopératoire dans les cas de chirurgie de la région du quatrième ventricule. Méthode/technique: Nous décrivons l'utilisation d'un cathéter ventriculaire latéral placé de façon conventionnelle pour faciliter l'irrigation ventriculaire antérograde pendant la chirurgie de la région du quatrième ventricule. Cette technique offre une alternative sûre aux approches conventionnelles de l'irrigation du quatrième ventricule et évite d'avoir recours à la mise en place d'un cathéter dans le troisième ou le quatrième ventricule et/ou à des ponctions lombaires répétées en évacuant complètement le sang et les débris tissulaires du champ opératoire pendant la chirurgie. Résultats: Les résultats préliminaires obtenus sur cinq ans montrent que moins de patients ont eu besoin d'une dérivation ventricule-péritonéale de façon précoce (5\%) ou tardive (10\%). Conclusion: Cette technique est une méthode sûre pour diminuer l'hydrocéphalie postopératoire suite à une chirurgie de la région du quatrième ventricule.

Can. J. Neurol. Sci. 2005; 32: 57-60

With posterior fossa pathology, hydrocephalus is common both at the time the patient presents and as a postoperative concern. Pre-operatively this is often due to obstruction of flow through the ventricular system from tumour mass effect. ${ }^{1}$ Postoperatively it can be a result of persistent mass effect (ie. with incomplete decompression of the fourth ventricle), failure of cerebrospinal fluid (CSF) absorption or iatrogenic obstruction of the aqueduct of Sylvius secondary to blood or surgical debris. Small amounts of clotted blood may also eventually contribute to development of communicating hydrocephalus. There have been advocates for and against managing pre-operative hydrocephalus with ventriculostomy or CSF shunt prior to tumour removal. Hoffman maintains that there is a risk of tumour shift with ventricular decompression that can lead to hemorrhage and deterioration and therefore recommends against this approach. ${ }^{2}$ The management of hydrocephalus in the pre-operative period must be individualized and there are certainly instances in which urgent treatment is required. ${ }^{1}$ More typically, stable patients with frank hydrocephalus are treated with high dose corticosteroids and a ventricular drain is placed as part of the tumour operative procedure or postoperatively to "decompress" the ventricles and drain blood that may incite postoperative hydrocephalus.,

In an effort to prevent postoperative hydrocephalus, a number of different surgical techniques have been utilized. These include: (1) intra-operative irrigation of the excision cavity including the region of the fourth ventricle to remove blood and tissue debris; (2) placement of a ventricular catheter into either the fourth ventricle or third ventricle from the fourth ventricle via the aqueduct of Sylvius; (3) use of a Lapras catheter (from third ventricle to cisterna Magna via the aqueduct and fourth ventricle); (4) temporary ventriculo-subgaleal shunting; and (5)

From the Division of Neurosurgery, Dalhousie University, Department of Surgery, Halifax Infirmary, Halifax, NS (IGF); and University of Calgary, Department of Clinical Neurosciences, Alberta Children's Hospital, Calgary, AB (MGH); Canada. ReCeived January 3, 2001. Acceptedinfinalform August 4, 2004. Reprint requests to: Mark G. Hamilton, Department of Neurosurgery, University of Calgary, Department of Clinical Neurosciences, Alberta Children's Hospital, 1820 Richmond Road SW, Calgary, AB, T2T5C7 Canada. 
single or serial lumbar punctures to facilitate and promote anterograde flow through the ventricular system. However, we could find few reports describing clinical experience with these various techniques. According to some studies, 12-90\% of all pediatric patients with posterior fossa tumours will require ventriculo-peritoneal (VP) shunt after surgical treatment of their tumour ${ }^{5,6}$

We describe a technique developed by the senior author $(\mathrm{MGH})$ that involves utilizing the external ventricular drain typically inserted at the beginning of the tumour operation (or at the time of presentation if they are significantly symptomatic from their hydrocephalus). This allows irrigation of the posterior fossa in an anterograde fashion from the depth of the operative field at the completion of the procedure. We have initiated this technique in an attempt to reduce the risks of postoperative hydrocephalus and feel that we have seen a reduction in the need for chronic ventricular drainage or ventricular shunting after surgical resection of a fourth ventricular tumour. Moreover, we feel this goal is achieved in a safe, controlled fashion. Although most applicable to a pediatric population due to the more frequent occurrence of fourth ventricular pathology, this technique can be used in appropriately selected adult patients.

\section{TeChNiQue}

Appropriate patients are defined as those with a fourth ventricular tumour and resultant hydrocephalus. We use either a right frontal or right parieto-occipital external ventricular drain placement. The technique for placement of either a frontal or parieto-occipital catheter is well-known to all neurosurgeons and does not require further elaboration here. ${ }^{7}$ Care is taken not to lose an excessive volume of CSF prior to dural opening. During patient positioning in a prone or Concorde position, utmost care is taken to avoid inadvertent catheter movement. The operation then proceeds in a standard fashion. The ventricular catheter is connected to a standard CSF collection system. One end of an appropriate length of sterile intravenous extension tubing (primed with lactated Ringer's solution and with a syringe attached to the surgeon's end) is passed from the operative field to the anesthetist who, in turn, connects the tubing to the ventricular drainage system at the site of a three-way stopcock. The stopcock is adjusted such that the system is turned "off" to the drainage bag, giving the surgeon complete control of the ventricular drain. The surgical procedure is performed as it normally would be. At the completion of the procedure, but prior to closure, the operative field is irrigated. Conventionally, this would require flushing of irrigant into and through the fourth ventricle region from the operative field with the possibility of displacing tissue debris and clotted blood into the cerebral aqueduct, or ultimately into the third ventricle. After first ensuring that the ventricular catheter tip is appropriately positioned by allowing spontaneous drainage of CSF, sterile irrigant, typically lactated Ringer's solution, is gently flushed through the ventricular drainage system in an anterograde fashion and appears in the fourth ventricle. The cautious instillation of irrigant is performed only by the surgeon and any resistance in the system constitutes a reason to re-assess catheter placement or abandon the procedure. The fluid used is at room temperature and because excess fluid is aspirated from the surgical field, there is no specific maximum volume. Debris or blood is washed into the fourth ventricle rather than in the opposite direction. This debris and fluid is then easily aspirated from the field using gentle suction. There is no direct irrigation onto the floor of the fourth ventricle. Irrigation is continued until the fluid appearing in the fourth ventricle is clear and free of debris and blood. In consultation with the anaesthetist, constant attention is paid to blood pressure and heart rate during and following the irrigation procedure.

For obvious reasons we would never recommend this technique for patients with aqueduct stenosis or obstructive lesions proximally in the ventricular system that prohibit communication between the ventricular catheter and the fourth ventricle. We would also not employ this technique if we deemed that an external ventricular drain was not required during patient management.

\section{ReSUlts}

This technique has been applied prospectively in 20 consecutive patients with tumours of the fourth ventricle producing obstructive hydrocephalus (with no pre-existing shunt in place) operated by the senior author $(\mathrm{MGH})$ over a four-year period. Nineteen patients $(95 \%)$ had a gross total resection at the time of clinical presentation achieved by either a single procedure $(95 \%)$ or a two-stage procedure $(5 \%)$. Only one patient $(5 \%)$ required a shunt in the early postoperative period (two weeks) and only two patients $(10 \%)$ required shunts in a delayed fashion because of tumour recurrence (11 months and 13 months postoperatively). There have been no adverse events related directly or indirectly to this irrigation technique.

\section{DISCUSSION}

The usefulness of this new procedure will ultimately be determined by its ability to reduce the need for CSF shunts in patients with posterior fossa tumours. Wide ranges of patients with posterior fossa tumours have been reported in the context of their need for a VP shunt. The best results were reported by the group at British Columbia Children's Hospital. ${ }^{5}$ In reviewing their 105 pediatric patients with all types of posterior fossa tumours, only $12 \%$ required acute or delayed VP shunts. These results are exceptional and most authors have demonstrated a greater tendency to shunt patients. On the other extreme, Griwan and colleagues ${ }^{6}$ described their experience in a developing country where 64 of 70 patients $(91 \%)$ with posterior fossa tumours required a shunt pre-operatively because patients tended to present in the late stages of disease.

Many other groups have reported shunting rates between these two extremes. Dias and Albright estimated that in the management of posterior fossa tumours, between two-thirds and three-quarters of patients could be managed with a peri-operative ventriculostomy. ${ }^{8}$ In a review of 175 children treated with various posterior fossa tumours, Kumar et $\mathrm{al}^{9}$ discovered that a postoperative VP shunt was necessary in $19 \%$ of patients, with factors contributing to need for shunt placement including age of the patient, completeness of tumour resection and tumour type. Rekate et al ${ }^{10}$ reported the need for a shunt in $25 \%$ of patients in the acute postoperative period. Lee et al $^{11}$ reviewed 42 patients with medulloblastoma who were initially managed without a 
shunt. They found that within four weeks of surgery, $40 \%$ of patients required a VP shunt. Albright and colleagues ${ }^{12}$ analyzed a series of 141 children with medulloblastoma and found that $91 \%$ of them had hydrocephalus. Fifty percent of these patients required an external ventricular catheter, while $60 \%$ ultimately required a VP shunt. Smoots and colleagues ${ }^{13}$ retrospectively evaluated 78 children with cerebellar astrocytomas. Fifty-eight patients $(74 \%)$ required a ventriculostomy $(>62 \%)$ or shunt either pre- or intra-operatively, while 19 patients eventually required a postoperative shunt. Finally, the recent report of Modha and colleagues ${ }^{14}$ described the need for VPshunt in 17 of $21(81 \%)$ pediatric medulloblastoma patients who presented with hydrocephalus, comprising $47 \%$ of their entire series. Shunts were placed pre-operatively in seven patients, and intra- or postoperatively in the remaining ten. The need for VP shunt was independent of degree of tumour removal. This differs from the findings of Culley et al, ${ }^{15}$ who had to place VP shunts in $63 \%$ of their 117 patients. The need for a shunt was associated with subtotal resection, young age at diagnosis, involvement of midline structures, prolonged external ventricular drainage, CSF infections, pseudomeningocele formation and cadaveric dural grafts. Although the numbers vary in these series, it can be summarized that a significant population of children with posterior fossa tumours require a peri-operative ventriculostomy or become shunt dependent. Although the size of our study group is smaller than some of these series, it would appear that the use of this irrigation technique might impact the rate of postoperative hydrocephalus, based on our preliminary results.

It is, therefore, established that a significant portion of patients with posterior fossa tumours may require a VP shunt. Lee and colleagues ${ }^{11}$ determined that patients who had hydrocephalus that was not managed pre-operatively had a higher incidence of postoperative pseudobulbar syndrome and recommended CSF diversion in the peri-operative period to avoid such neurological complications. Consideration is then needed for why a shunt should be avoided. The strongest reason is the multitude of complications that are associated with VP shunts. ${ }^{16}$ Another issue is the impact of a shunt on prognosis of the patient, which few authors have considered. Jenkin et al ${ }^{17}$ found that five-year survival in medulloblastoma patients, irrespective of adjuvant radiation treatment, was better for patients who did not have a VP shunt placed. They did not attribute worsened outcome to CSF diversion and the degree of hydrocephalus was not related to outcome in a multivariate analysis. They speculated that patients who required a VP shunt likely had factors affecting prognosis other than hydrocephalus. With respect to metastatic disease, Belza and colleagues ${ }^{18}$ found that the presence or absence of a shunt made no significant difference in the 77 patients they evaluated retrospectively. Modha et al ${ }^{14}$ did not witness any CSF shunt metastases in their patients with medulloblastoma and did not see any difference in survival attributable to shunt placement. Goel ${ }^{19}$ also did not have any patients with trans-shunt metastases in his series of 62 patients with posterior fossa tumours. However, there is some evidence that VP shunting may worsen prognosis. David and colleagues $^{20}$ recently demonstrated worse five-year survival for medulloblastoma patients requiring CSF diversion within 30 days of surgery and this may constitute another reason for attempting to avoid a VPshunt by using a technique such as ours.
This technique makes use of a ventricular catheter that would normally be placed during the course of this type of operation and thus does not add morbidity or time to the procedure. It is safer than other methods of fourth ventricular irrigation because it avoids direct irrigation on the floor of the fourth ventricle and the need for introduction of a ventricular catheter into the third ventricle through the aqueduct. Although we found few reports in the literature specifically implicating such maneuvers in morbidity, there is a strong likelihood that any adverse outcome they cause would be attributed to the primary procedure (ie. brain tumour removal). In a report describing endoscopic aqueductoplasty, complications related to aqueduct manipulation included permanent or transient diplopia due to aqueductal roof injury and transient trochlear palsy in nearly $30 \%$ of patients. ${ }^{21}$ In discussing the complications of fourth ventricular shunts, Lee et $\mathrm{al}^{22}$ reported that $42 \%$ of patients suffered complications related to fourth ventricular catheter placement including cranial nerve dysfunction and catheter misplacement. This newly reported technique spares the patient from having to undergo any direct or indirect manipulation of the aqueduct or fourth ventricle as well as avoiding serial lumbar punctures following the operation. It also allows a ventricular catheter to reside in a more conventional location than would an intra-operatively placed third or fourth ventricular catheter. Unlike the procedure of ventriculo-subgaleal shunting, which also aims to avoid the need for an external drainage system, our technique does not necessarily require that an indwelling catheter be left beyond the completion of the operative procedure. Furthermore, preliminary evidence in this small series of patients indicates that this irrigation technique may reduce the incidence of postoperative hydrocephalus and decrease the need for a VP shunt. However, further clinical experience will be required to substantiate this early impression.

\section{REFERENCES}

1. Schmidek HH. Surgical management of cerebellar tumours in adults. In: Schmidek $\mathrm{HH}$, Sweet WH (Eds). Operative Neurosurgical Techniques: Indications, Methods and Results. Philadelphia: WB Saunders, 1995: 791-800.

2. Hoffman HJ. Ependymomas and fourth ventricular tumours. In: Apuzzo M J (Ed). Brain Surgery: Complication Avoidance and Management. New York: Churchill Livingstone, 1993: 1849-1860.

3. Albright L. Posterior fossa tumors. Neurosurg Clin N Am 1992; 3 : 881-891.

4. Petronio J, Walker ML. Surgical management of cerebellar tumours in children. In: Schmidek HH, Sweet WH (Eds). Operative Neurosurgical Techniques: Indications, Methods and Results. Philadelphia: WB Saunders, 1995: 801-812.

5. Cochrane DD, Gustavsson B, Poskitt KP, Steinbok P, Kestle JR. The surgical and natural morbidity of aggressive resection for posterior fossa tumors in childhood. Pediatr Neurosurg 1994; 20: 19-29.

6. Griwan MS, Sharma BS, Mahajan RK, Kak VK. Value of precraniotomy shunts in children with posterior fossa tumours. Childs Nerv Syst 1993; 9: 462-466.

7. Mapstone TB, Ratcheson RA. Techniques of ventricular puncture. In: Wilkins RH, Rengachary SS (Eds). Neurosurgery. New York: McGraw Hill, 1996: 179-184.

8. Dias MS, Albright AL. Management of hydrocephalus complicating childhood posterior fossa tumors. Pediatr Neurosci 1989; 15: 283-290.

9. Kumar V, Phipps K, Harkness W, Hayward RD. Ventriculoperitoneal shunt requirement in children with posterior fossa tumours: an 11-year audit. Br J Neurosurg 1996; 10: 467-470. 
10. Rekate HL, McCormick J, Yamada K. An analysis of the need for shunting after brain tumour surgery. In: Marlin AE (Ed). Concepts in Pediatric Neurosurgery. Basel: S. Karger Publishing, 1991: 39-46.

11. Lee M, Wisoff JH, Abbott R, Freed D, Epstein FJ. Management of hydrocephalus in children with medulloblastoma: prognostic factors for shunting. Pediatr Neurosurg 1994; 20: 240-247.

12. Albright AL, Wisoff JH, Zeltzer PM, et al. Current neurosurgical treatment of medulloblastomas in children. A report from the Children's Cancer Study Group. Pediatr Neurosci 1989; 15: 276282.

13. Smoots DW, Geyer JR, Lieberman DM, Berger MS. Predicting disease progression in childhood cerebellar astrocytoma. Childs Nerv Syst 1998; 14: 636-648.

14. Modha A, Vassilyadi M, George A, et al. Medulloblastoma in children - the Ottawa experience. Childs Nerv Syst 2000; 16: 341-350.

15. Culley DJ, Berger MS, Shaw D, Geyer R. An analysis of factors determining the need for ventriculoperitoneal shunts after posterior fossa tumor surgery in children. Neurosurgery $1994 ; 34$ : 402-408.

16. Cinalli G. Alternatives to shunting. Childs Nerv Syst 1999; 15: 718-731.

17. Jenkin D, Shabanah MA, Shail EA, et al. Prognostic factors for medulloblastoma. Int J Radiat Oncol Biol Phys 2000; 47: 573-584.

18. Belza MG, Donaldson SS, Steinberg GK, Cox RS, Cogen PH. Medulloblastoma: freedom from relapse longer than 8 years $-\mathrm{a}$ therapeutic cure? J Neurosurg 1991; 75: 575-582.

19. Goel A. Whither preoperative shunts for posterior fossa tumours? Br J Neurosurg 1993; 7: 395-399.

20. David KM, Casey AT, Hayward RD, et al. Medulloblastoma: is the 5-year survival rate improving? A review of 80 cases from a single institution. J Neurosurg 1997; 86: 13-21.

21. Schroeder HW, Gaab MR. Endoscopic aqueductoplasty: technique and results. Neurosurgery 1999; 45: 508-515.

22. Lee M, Leahu D, Weiner HL, et al. Complications of fourthventricular shunts. Pediatr Neurosurg 1995; 22: 309-314. 